Coor di nat i on Hel i cal Nano- $t$ ubes Const ruct ed by Met al (II) I ons wi th the I ndi cat or Chrome Pure $\mathrm{Bl}$ ue $\mathrm{BX}$

\begin{tabular}{|l|l|}
\hline 著者 & $\begin{array}{l}\text { Sohmina Aki ko, Okuyana Tadashi , Suzuki Ryohei , } \\
\text { Yamani shi Kat sunor i , Sugi not o Kuni hi sa, Kondo } \\
\text { M t sur u }\end{array}$ \\
\hline $\begin{array}{l}\text { j our nal or } \\
\text { publ i cat i on ti t l e }\end{array}$ & Chemi st ry Let ter s \\
\hline vol une & 46 \\
\hline nunber & 4 \\
\hline page range & $485-488$ \\
\hline year & $2017-01-24$ \\
\hline 出版者 & 日本化学会 \\
\hline 権利 & $\begin{array}{l}\text { Copyr i ght ( C) 2017 The Chem cal Soci et y of } \\
\text { Japan. Al I Ri ght s Reserved. }\end{array}$ \\
\hline URL & ht t p: //hdl . handl e. net /10297/10340 \\
\hline
\end{tabular}




\title{
Coordination Helical Nano-tubes Constructed by Metal(II) Ions with the Indicator Chrome Pure Blue BX
}

\author{
Akiko Sohmiya, ${ }^{1}$ Tadashi Okuyama, ${ }^{1}$ Ryohei Suzuki, ${ }^{1}$ Katsunori Yamanishi,${ }^{\dagger 2}$ Kunihisa Sugimoto ${ }^{3}$ and Mitsuru Kondo $* 1,4$ \\ ${ }^{1}$ Department of Chemistry, Faculty of Science, Shizuoka University, 836 Ohya, Suruga-ku, Shizuoka, 422-8529 \\ ${ }^{2}$ Graduate School of Science and Technology, Shizuoka University, 836 Ohya, Suruga-ku, Shizuoka, 422-8529 \\ ${ }^{3}$ Japan Synchrotron Radiation Research Institute, 1-1-1, Kouto, Sayo-cho, Sayo-gun, Hyogo, 679-5198 \\ ${ }^{4}$ Green Chemistry Research Division, Research Institute of Green Science Technology, Shizuoka University, \\ 836 Ohya, Suruga-ku, Shizuoka 422-8529 \\ ${ }^{\dagger}$ Current address: Institute for Molecular Science, Okazaki, Aichi 444-8787, Japan
}

(Received <Month><Date>, <Year >; CL-<No>; E-mail: kondo.mitsuru@ shizuoka.ac.jp)

A treatment of $\mathrm{MCl}_{2}(\mathrm{M}=\mathrm{Zn}, \mathrm{Ni}, \mathrm{Co}, \mathrm{Mg})$ with the indicator chrome pure blue $\mathrm{BX}\left(\mathrm{Na}_{2} \mathrm{cpb}\right)$ yielded new coordination polymers, $\left\{\left[\mathrm{M}\left(\mathrm{H}_{2} \mathrm{O}\right)_{6}\right]\left[\mathrm{M}(\mathrm{cpb})_{2}\left(\mathrm{H}_{2} \mathrm{O}\right)_{2}\right] \cdot\left(\mathrm{H}_{2} \mathrm{O}\right)_{9}\right\}_{\mathrm{n}}$ $(\mathrm{M}=\mathrm{Zn}(\mathbf{1}), \quad \mathrm{Ni}$ (2), $\mathrm{Co}(\mathbf{3}))$ and $\left\{\left[\mathrm{Mg}\left(\mathrm{H}_{2} \mathrm{O}\right)_{6}\right]\left[\mathrm{Mg}(\mathrm{cpb})_{2}\left(\mathrm{H}_{2} \mathrm{O}\right)_{2}\right] \cdot\left(\mathrm{H}_{2} \mathrm{O}\right)_{6}\right\}_{\mathrm{n}} \quad$ (4)). These compounds, which are crystallographically isostructural, show helical 1D nano-tube structures.

Coordination polymers bearing organic bridging ligands with large conjugating system have attracted intense attention to prepare coordination materials with new network motifs and various properties based on the ligands. ${ }^{1-3}$ For example, numerous coordination polymers have been prepared by using organic bridging ligands with porphyrin component. ${ }^{2}$

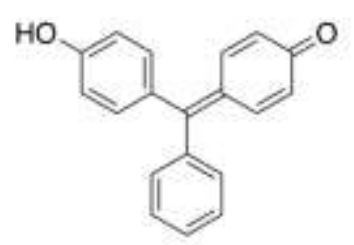

hpmc framework

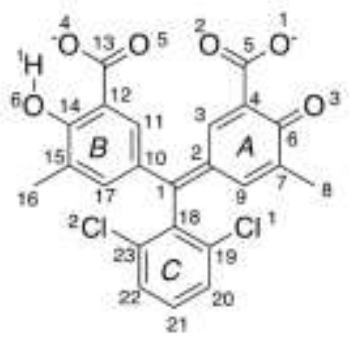

$\mathrm{cpb}$
Scheme 1. Hpmc framework (left) and structure of cpb (right) with numbering scheme used in this paper for structural description.

4-[(4-Hydroxyphenyl)(phenyl)methylene]-2,5cyclohexadien-1-one (hpmc) (Scheme 1) is one of the wellknown organic frameworks with large conjugating system. ${ }^{3}$ Their frameworks are observed in many compounds such as dyes, ${ }^{4} \mathrm{pH}$ indicators, ${ }^{5}$ and organic devices. ${ }^{6}$ Although coordination polymers which incorporate the hpmc component is promising to prepare the coordination polymers with new properties, the synthetic studies have not been explored well to date.

Dicarboxylate compounds such as terephthalate are useful for bridging ligands to prepare coordination polymers. ${ }^{7}$ For compounds with hpmc framework, some of them have two carboxylate groups, which would be useful as a bridging ligand to prepare new coordination polymers. For example, 5[(3-carboxy-5-methyl-4-oxo-2,5-cyclohexadien-1ylidene)(2,6-dichlorophenyl)methyl]-2-hydroxy-3methylbenzoate (cpb; Scheme 1), whose sodium salt is known as $\mathrm{pH}$ indicator chrome pure blue $\mathrm{BX}$, has two carboxylate groups that bind to metal ions. We have selected the cpb as a bridging ligand for the synthesis of new coordination polymers in this work, and have successfully obtained coordination polymers with unique nano-tube frameworks. Here, we report the syntheses and the unique structures of the coordination polymers $\left\{\left[\mathrm{M}\left(\mathrm{H}_{2} \mathrm{O}\right)_{6}\right]\left[\mathrm{M}(\mathrm{cpb})_{2}\left(\mathrm{H}_{2} \mathrm{O}\right)_{2}\right] \cdot\left(\mathrm{H}_{2} \mathrm{O}\right)_{9}\right\}_{\mathrm{n}}$ $(\mathrm{M}=\mathrm{Zn}(\mathbf{1}), \quad \mathrm{Ni} \quad(\mathbf{2}), \quad \mathrm{Co} \quad(\mathbf{3}))$ and $\left\{\left[\mathrm{Mg}\left(\mathrm{H}_{2} \mathrm{O}\right)_{6}\right]\left[\mathrm{Mg}(\mathrm{cpb})_{2}\left(\mathrm{H}_{2} \mathrm{O}\right)_{2}\right] \cdot\left(\mathrm{H}_{2} \mathrm{O}\right)_{6}\right\}_{n}$ (4)). To the best of our knowledge, this is the first example of coordination polymers that incorporate the hpmc units in the framework.

Compound 1 was isolated as orange-plate crystals from reaction mixture of $\mathrm{Na}_{2} \mathrm{cpb}(25 \mathrm{mg}, 0.050 \mathrm{mmol})$ and $\mathrm{ZnCl}_{2}$ (6.8 mg, $0.050 \mathrm{mmol})$ in $30 \mathrm{~mL}$ of $\mathrm{H}_{2} \mathrm{O} / \mathrm{EtOH}(2 / 1 ; \mathrm{v} / \mathrm{v})$ within one week. Compound 2-4 were also isolated as orangeplate crystals by similar procedure for preparation of $\mathbf{1}$ (summarized in SI). Their orange colors, which are not dependent on the kinds of metal ions, are due to the cpb component (vide infra). Since 1-4 were crystallographically isostructural, crystal structure of $\mathbf{1}$ is described here for structural descriptions of the compounds prepared in this work. $^{8}$

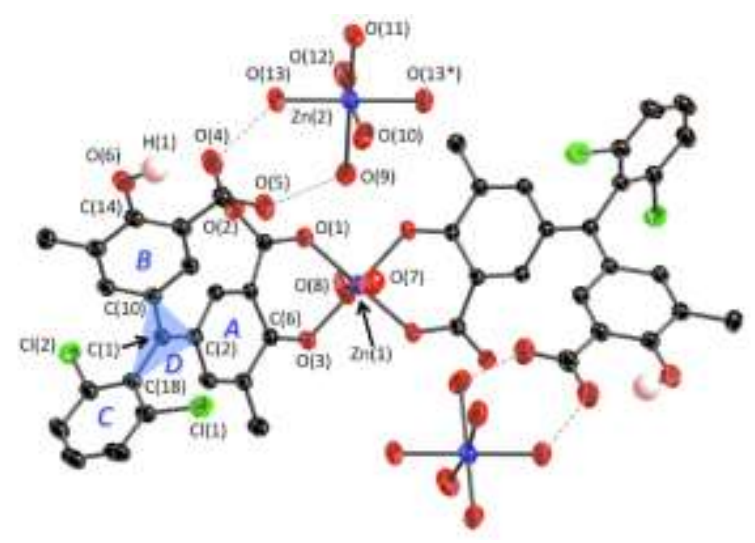

Figure. 1 Thermal ellipsoids of coordination environments around the $\mathrm{Zn}^{\mathrm{II}}$ centers of $\mathbf{1}$ at $30 \%$ probabilities. Disordered water molecules, which bind to the $\mathrm{Zn}(2)$ atom, and hydrogen atoms except for $\mathrm{H}(1)$ are omitted for clarity. Color code: blue, zinc; red, oxygen; green, chlorine; pink, hydrogen; black, carbon. Symmetry operation * $1 / 2-X, 1 / 2-Y,+Z$. The planes $A, B$, and $C$ are shown in the capital letters, and the plane $D$ is exhibited by the blue colored triangle.

Figure 1 shows the two cationic units $\left[\mathrm{Zn}^{\mathrm{II}}\left(\mathrm{H}_{2} \mathrm{O}\right)_{6}\right]^{2+}$ and an anionic part $\left[\mathrm{Zn}^{\mathrm{II}}(\mathrm{cpb})_{2}\left(\mathrm{H}_{2} \mathrm{O}\right)_{2}\right]^{2-}$. As illustrated in Scheme 1 , the cpb contains three ring units designated as $A, B$, and $C$, 
which are connected by the carbon atom $\mathrm{C}(1)$. The $\operatorname{ring} A$ is based on a quinone-methide framework having carboxylate and methyl groups, while the ring $B$ is a phenyl ring bearing carboxylate, hydroxy, and methyl groups. The ring $C$ is a phenyl ring with two $\mathrm{Cl}$ substituents at the $o$-positions.

The carbon atom $\mathrm{C}(1)$ and the three carbon atoms, $\mathrm{C}(2)$, $\mathrm{C}(10)$, and $\mathrm{C}(18)$, which bind to $\mathrm{C}(1)$ atom, are in the same plane. This $\mathrm{C}_{4}$ plane is defined by the plane $D$. (Figure 1 ) The $\mathrm{C}(1)-\mathrm{C}(2)$ distance $(1.377$ (3) $\AA$ ) is significantly shorter than those of $\mathrm{C}(1)-\mathrm{C}(10)$ and $\mathrm{C}(1)-\mathrm{C}(18)$ bonds $(1.462$ (3) and 1.393 (3) A) because of the double bond character.

The bond distances observed in the ring $A$ of the cpb in $\mathbf{1}$ reflect the quinone-methide backbone illustrated in the Scheme 1. The $C(3)-C(4)$ and $C(7)-C(9)$ distances (1.351 (3) $\AA$ and 1.355 (3) $\AA$ ) are significantly shorter than those of other four $\mathrm{C}-\mathrm{C}$ bonds in the 6 -membered ring, which range from 1.434 (3) to 1.462 (3) $\AA$ (avg. $1.45 \AA$ ). The $\mathrm{C}(6)-\mathrm{O}(3)$ distance $(1.252$ (3) $\AA$ ) is close to that of the $\mathrm{C}=\mathrm{O}$ bond distance of benzoquinone (about $1.22 \AA),{ }^{9}$ and remarkably shorter than that of the $\mathrm{C}-\mathrm{O}$ bond generally observed in the phenol (about $1.36 \AA) .{ }^{10}$

In the ring $B$, the $\mathrm{C}-\mathrm{C}$ bond distances of the 6membered ring range from 1.374 (3) to 1.408 (3) $\AA$ (avg. $1.396 \AA$ ), which are general for the $\mathrm{C}-\mathrm{C}$ distances observed in the delocallized phenyl rings. The $\mathrm{C}(14)-\mathrm{O}(6)$ distance (1.346 (3) $\AA$ ) is significantly longer than the $\mathrm{C}(6)-\mathrm{O}(3)$ distance (1.252 (3) $\AA$ ), and closes to that of $\mathrm{C}$ - $\mathrm{O}$ distance observed in the phenol (about $1.36 \AA)^{10}$. The $\mathrm{C}-\mathrm{C}$ bond distances in the 6-membered ring of the ring $C$, which range from $1.367(5)$ to $1.397(3) \AA$ (avg. $1.383 \AA$ ), are also general as a delocallized phenyl ring. The hydrogen atom $\mathrm{H}(1)$ of the hydroxy group bound in the ring $B$ forms a hydrogen bond with the carboxylate oxygen atom $\mathrm{O}(4)(\mathrm{O}(4) \cdots \mathrm{O}(6)=2.511$ (3) ^).

The rings $A$ and $B$ have coordination sites, which are carboxylate and carbonyl groups for the ring $A$, and carboxylate and hydroxy groups for the $\operatorname{ring} B$. In the anionic part, the two cpb bind to the $\mathrm{Zn}^{\mathrm{II}}$ center $(\mathrm{Zn}(1))$ at the carboxylate oxygen atom $(\mathrm{O}(1))$ and the carbonyl oxygen atom $(\mathrm{O}(3))$ in the equatorial plane as shown in Figure 1. Coordinations of the two water molecules, $\mathrm{O}(7)$ and $\mathrm{O}(8)$, in the axial sites provide the octahedral geometry around the $\mathrm{Zn}(1)$ center. The $\mathrm{Zn}(1)-\mathrm{O}(7)$ and $\mathrm{Zn}(1)-\mathrm{O}(8)$ distances (2.148 (3) and 2.118(4) $\AA$ ) are slightly longer than those of $\mathrm{Zn}(1)-\mathrm{O}(1)$ and $\mathrm{Zn}(1)-\mathrm{O}(3)$ distances $(2.0058$ (17) and 2.0883 (16) $\AA$ ). There is a crystallographic C2 axis through the $\mathrm{O}(7)-\mathrm{Zn}(1)-\mathrm{O}(8)$ bond.

The four water molecules $(\mathrm{O}(9)-\mathrm{O}(12))$ that bind to the zinc atom $\mathrm{Zn}(2)$ in the $\left[\mathrm{Zn}^{\mathrm{II}}\left(\mathrm{H}_{2} \mathrm{O}\right)_{6}\right]^{2+}$ unit are disordered at the two positions by the $\mathrm{C} 2$ axis which runs through the $\mathrm{Zn}(2)$ atom and in the $\mathrm{O}_{4}$ plane defined by the $\mathrm{O}(9)-\mathrm{O}(12)$ atoms (Figure $\mathrm{S} 1 \mathrm{a}$ in Supporting Information (SI)). Their four disordered oxygen atoms were refined as $50 \%$. The carboxylate and hydroxy groups bound in the $\operatorname{ring} B$ do not coordinate to the $\mathrm{Zn}^{\mathrm{II}}$ center, but form hydrogen bonds with the water molecules of the cationic unit $(\mathrm{O}(4) \cdots \mathrm{O}(13)=2.694$ (3) $\AA, \mathrm{O}(5) \cdots \mathrm{O}(9)=2.615(5) \AA)$ as shown in Figure 1 . Hydrogen bonding interactions formed by the disordered water molecules are shown in Figure S1b in SI.
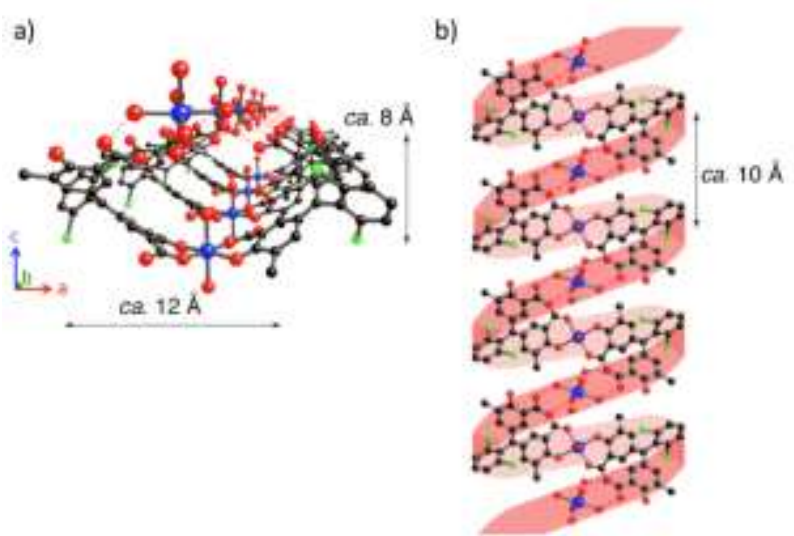

Figure. 2 Perspective view of the helical tube of $\mathbf{1}$ along the $b$ axis (a) and the helical structure as viewed along the $c$ axis (b).
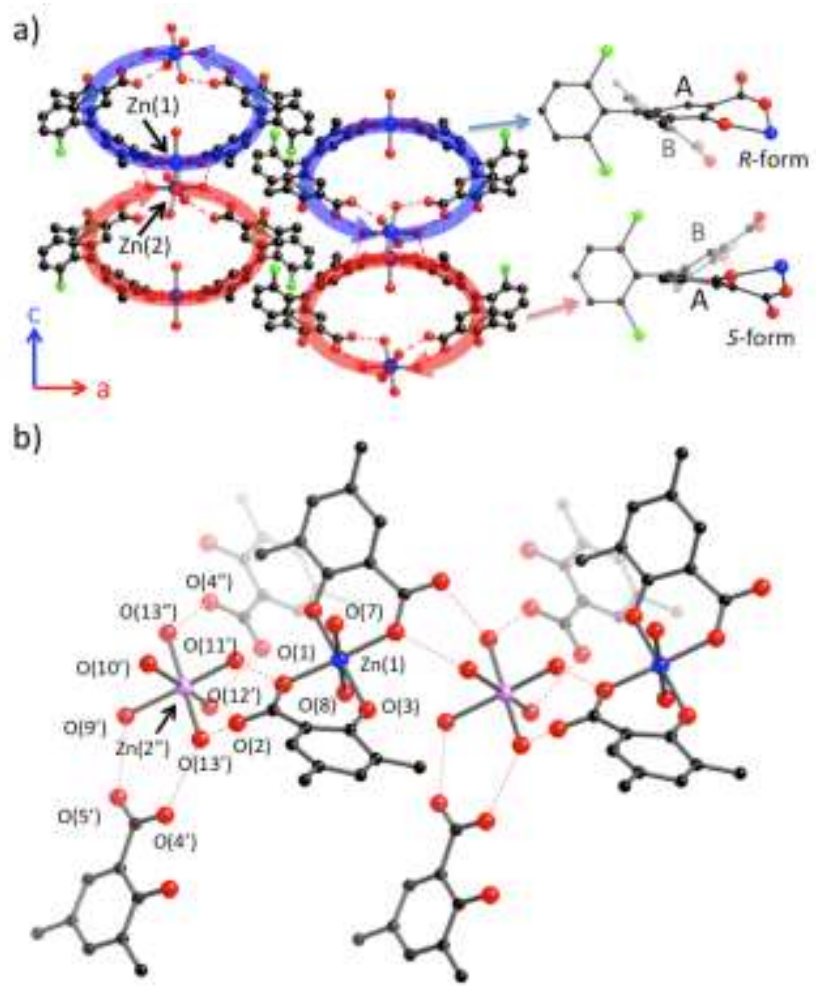

Figure. 3 View of the stacking aspects of the right- and lefthanded helical tubs which are distinguished by different color ribbons for 1 (a) with illustrations of the $R$-formed and $S$ formed structures of the cpb incorporated in the framework. Perspective view of the hydrogen bonding interactions which connect the $\left[\mathrm{Zn}^{\mathrm{II}}\left(\mathrm{H}_{2} \mathrm{O}\right)_{6}\right]^{2+}$ units with the anionic part in the adjacent tube framework (b). Hydrogen atoms are omitted for clarity. $\mathrm{Zn}(1)$ and $\mathrm{Zn}(2)$ are colored by blue and purple in (b). Color code: blue and purple, zinc; red, oxygen; green, chlorine; black, carbon. Symmetry operation ' $1 / 2-\mathrm{X}, \mathrm{Y}, 1 / 2+\mathrm{Z}$, ” X, $1 / 2-\mathrm{Y}, 1 / 2+\mathrm{Z}$.

The hydrogen bonding connections of the anionic units $\left[\mathrm{Zn}^{\mathrm{II}}(\mathrm{cpb})_{2}\left(\mathrm{H}_{2} \mathrm{O}\right)_{2}\right]^{2-}$ and the cationic units $\left[\mathrm{Zn}^{\mathrm{II}}\left(\mathrm{H}_{2} \mathrm{O}\right)_{6}\right]^{2+}$ yield the unique helical framework, which runs along the $b$ axis, as exhibited in Figure 2. It shows the compressed tube structure with a size of about $12 \AA$ and $8 \AA$ in width and height (Figure 
2a), and shows about $10 \AA$ A repetition (Figure $2 b$ ). The channel size created in the helical tube is about $3 \times 3 \AA^{2}$, which are filled with remarkably disordered water molecules (Figure S2 in SI), which were solved at $50 \%$ or $25 \%$ occupancies.

The cpb shows the two deviated structures in $\mathbf{1}$. The ring $A$ and $B$ bend up or down from the plane $D$ like scissors as exhibited in Figure 3a. The $\mathrm{C}(6)$ and $\mathrm{C}(14)$ atoms are located

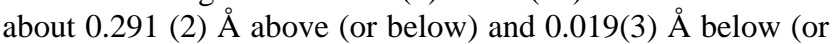
above) the plane $D$. The plane-plane angles defined by the plane $D$ and the each ring $(A, B$, or $C)$ are $14.26(5)^{\circ}, 36.5(6)^{\circ}$, and $95.91(7)^{\circ}$, respectively (Figure 1$)$.

The right-handed and left-handed helical frameworks are involved in the crystal structure. Since the rings $A$ and $B$ are not coplanar in the helical framework, the $\mathrm{cpb}$ ligand has the chiral structure in $\mathbf{1}$. The only $S$-formed cpb is involved in the right-handed framework, while only $R$-formed $\mathrm{cpb}$ is involved in the left-handed chiral framework (Figure 3a). The helical frameworks with opposite helicities stack alternately along the $c$ axis (Figure 3a).

As a screw stacks on another screw, it would fit sterically well when the directions of the coil of their screws have the same directions because their gears would bite well. It is noteworthy that the helical chains with opposite coiled directions stack alternately in $\mathbf{1}$. The tube frameworks which stack along the $c$ axis are connected by hydrogen bonds between the water molecules in the cationic $\left[\mathrm{Zn}^{\mathrm{II}}\left(\mathrm{H}_{2} \mathrm{O}\right)_{6}\right]^{2+}$ unit and the oxygen atoms of the carboxylate group in the ring A (Figure 3b) $\left(\mathrm{O}(1) \cdots \mathrm{O}\left(11^{*}\right)=2.618(6) \AA, \mathrm{O}(2) \cdots \mathrm{O}\left(13^{*}\right)=\right.$ 2.787 (3) $\AA$ ). As a result, 1 has a helical nano-tube assembled 2D structure, which expands in the $b c$ plane.

As mentioned above, all compounds 1-4 show intense orange colors due to the $\pi-\pi$ transition of the cpb. The indicator $\mathrm{Na}_{2} \mathrm{cpb}$ shows intense $\pi-\pi$ transition at $430 \mathrm{~nm}(\varepsilon=$ $\left.5.1 \times 10^{3} \mathrm{~cm}^{-1} \mathrm{M}^{-1}\right)$ in a $\mathrm{MeOH}$ and at about $500 \mathrm{~nm}$ in the solid state reflectance spectrum (Figure S6). The absorption spectra in $\mathrm{MeOH}$ and the solid state reflectance spectra of compound 1-4 show intense transitions at around $500 \mathrm{~nm}$ (Figure S6). These spectra are similar to those of $\mathrm{Na}_{2} \mathrm{cpb}$, revealing that the transitions of $\mathbf{1 - 4}$ are ascribed to the $\pi-\pi$ transition in the cpb (Figure S6).

Although 1-4 are isostructural, the rigidities of the crystal structures are not the same. Although fresh samples of compound $\mathbf{1}$ and $\mathbf{4}$ showed PXRD peaks, we couldn't observe intense PXRD peaks for compound $\mathbf{2}$ and $\mathbf{3}$ in spite of several attempts by using microcrystalline samples (Figure S7) because $\mathbf{2}$ and $\mathbf{3}$ changed to amorphous quickly under air by the releases of the guest water molecules. The larger chargeradius ratio (e/r) for $\mathrm{Zn}^{\mathrm{II}}$ and $\mathrm{Mg}^{\mathrm{II}}$ ions compared to those of $\mathrm{Co}^{\mathrm{II}}$ and $\mathrm{Ni}^{\mathrm{II}}$ ions would increase the rigidities of the tube frameworks for $\mathbf{1}$ and $\mathbf{4} .^{11}$

In summary, we have selected cpb, whose sodium salt is known as a $\mathrm{pH}$ indicator chrome pure blue $\mathrm{BX}$, as a bridging ligand to prepare new coordination polymers. The cpb has a hmpc unit bearing two dicarboxylate groups that bind to metal ions. We have successfully prepared four new coordination compounds 1-4, by treatments of metal source with $\mathrm{Na}_{2} \mathrm{cpb}$. Single crystal X-ray analyses demonstrated that 1-4 are isostructural, and have unique helical tube frameworks. These are the fist well characterized coordination polymers incorporating the hpmc units.
The authors thank Y. Yamamoto of Research Institute of Green Science and Technology in Shizuoka University for support in obtaining the elemental analysis data. This work was supported by the JSPS Grant-in-Aid for Scientific Research (C) (No. 15K05450).

Supporting Information is available on http://dx.doi.org

\section{References and Notes}

1. a) M. Yoshizawa, and J. K. Klosterman, Chem. Soc., Rev. 43, 1885-1898 (2014). b) J. Chen, A. Neels, and K. M. Fromm, Chem. Comm. 46, 8282-8284 (2010). c) R. Sakamoto, T. Iwashima, M. Tsuchiya, R. Toyoda, R. Matsuoka, J. F. Kögel, S. Kusaka, K. Hoshiko, T. Yagi, T. Nagayama, and H. Nishihara, J. Mater. Chem. A. 3, 15357-15371 (2015). d) D.Z. Wang, C.-S. Liu, J.-R. Li, L. Li, Y.-F. Zeng, and X.-H. Bu, CrystEngComm. 9, 289-297 (2007).

2 a) Z. Guo, and B. Chen, Dalton Trans. 44, 14574-14583 (2015). b) W.-Y. Gao, M. Chrzanowski, and S. Ma, Chem. Soc., Rev. 43, 5841-5866 (2014). d) B. F. Abrahams, B. F. Hoskins, D. M. Michail, and R. Robson, Nature 369, 727-729 (1994). e) B. F. Hoskins, and R. Robson, J. Am. Chem. Soc. 112, 1546-1554 (1990). f) H. Cui, Y. Wang, Y. Wang, Y.-Z. Fan, L. Zhang, and C.-Y. Su, CrystEngComm. 18, 2203-2209 (2016). g) Y. Diskin-Posner, G. K. Patra, and I. Goldberg, CrystEngComm. 4, (53), 296-301 (2002). h) Y. Diskin-Posner, and I. Goldberg, Chem. Comm., 1961-1962 (1999). i) Y. Diskin-Posner, S. Dahal, and I. Goldberg, Angew. Chem. Int. Ed. 39, (7), 1288-1292 (2000). j) W.-Y. Gao, C.-Y. Tsai, L. Wojtas, T. Thiounn, C.-C. Lin, and S. Ma, Inorg. Chem. 55, 7291-7294 (2016). k) W. Zhang, W. Gao, T. Pham, P. Jiang, and S. Ma, Cryst. Growth Des. 16, 1005-1009 (2016). 1) B. F. Abrahams, B. F. Hoskins, and R. Robson, J. Am. Chem. Soc. 113, 3606-3607 (1991). m) X.-S. Wang, L. Meng, Q. Cheng, C. Kim, L. Wojtas, M. Chrzanowski, Y.-S. Chen, X. P. Zhang, and S. Ma, J. Am. Chem. Soc. 133, 16322-16325 (2011). n) K.-J. Lin, Angew. Chem. Int. Ed. 38, (18), 2730-2732 (1999). o) M. E. Kosal, J.-H. Chou, S. R. Wilson, and K. S. Suslick, Nat. Mater. 1, 118-121 (2002). p) D. W. Smithenry, S. R. Wilson, and K. S. Suslick, Inorg. Chem. 42, 7719-7721 (2003). q) T. Ohmura, A. Usuki, K. Fukumori, T. Ohta, M. Ito, and K. Tatsumi, Inorg. Chem. 45, 7988-7990 (2006). r) Y. Kataoka, K. Kataoka, H. Murata, M. Handa, W. Mori, and T. Kawamoto, Inorg. Chem. Commun. 68, 37-41 (2016).

3 a) D. A. Shultz, S. H. Bodnar, R. K. Kumar, and J. W. Kampf, J. Am. Chem. Soc. 121, 10664-10665 (1999). b) S. K. Chandran, N. K. Nath, S. Roy, and A. Nangia, Cryst. Growth Des. 8, (1), 140-154 (2008). c) S. Takeda, H. Yamada, T. Mutai, I. Yoshikawa, and H. Houjou, Dyes Pigments 121, 372-378 (2015).

4 a) P. Rys, and H. Zollinger, in Fundamentals of the Chemistry and Application of Dyes, Wiley: London, 1972; pp 99-109. b) K. Machida, H. Lee, and T. Uno, J. Raman Spectrosc. 8, (3), 172-176 (1979).

5 E. Bányai, in Indicators, ed. Bishop, E., Pregamon press: Oxford, 1972; pp 65-176.

6 a) J. J. Lavigne, S. Savoy, M. B. Clevenger, J. E. Ritchie, B. McDoniel, S.-J. Yoo, E. V. Anslyn, J. T. McDevitt, J. B. Shear, and D. Neikirk, J. Am. Chem. Soc. 120, (25), 64296430 (1998). b) S. L. Wiskur, H. Ait-Haddou, J. J. Lavigne, and E. V. Anslyn, Acc. Chem. Res. 34, (12), 963-972 (2001). c) M. Comes, M. D. Marcos, R. Martínez-Máñez, F. Sancenón, J. Soto, L. A. Villaescusa, and P. Amorós, Chem. Comm., 3639-3641 (2008). d) D. Leung, J. F. Folmer- 
Andersen, V. M. Lynch, and E. V. Anslyn, J. Am. Chem. Soc. 130, (37), 12318-12327 (2008).

7 (a) M. Fujiwara, K. Seki, W. Mori, S. Takamizawa, Patent Nos. JP 09132580 (1995); EP 0727608 (1996). (b) W. Mori, F. Inoue, K. Yoshida, H. Nakayama, S. Takamizawa, M. Kishita, Chem. Lett. 1219-1220 (1997). (c) H. Li, M. Eddaoudi, T. L. Groy, and O. M. Yaghi, J. Am. Chem. Soc. 120, 8571-8572 (1998). (d) M. Eddaoudi, D. B. Moler, H. Li, B. Chen, T. M. Reineke, M. O'Keeffe, and O. M. Yaghi, Acc. Chem. Res. 34, 319-330 (2001).

8 Data collections were carried out on a Rigaku CCD Mercury system (monochromatic Mo K $\alpha$ radiation source) for $\mathbf{1}, \mathbf{2}$, and 3, and a Rigaku VariMax Saturn (Mo Ka radiation, 1.2 $\mathrm{kW}$ rotating anode) for 4. Crystallographic data for $\mathbf{1}$ : $\mathrm{C}_{46} \mathrm{H}_{62} \mathrm{Cl}_{4} \mathrm{O}_{29} \mathrm{Zn}_{2}$ (Mw: 1351.55), orthorhombic, space group $P$ ccn (No. 56),$a=31.2852$ (8), $b=10.3232$ (3), $c=19.7504$ (5) $\AA, \mathrm{V}=6378.7$ (3) $\AA^{3}, Z=4, \rho$ (cacld) $=1.407 \mathrm{gcm}^{-3}$, $\mu(\mathrm{MoK} \alpha)=1.000 \mathrm{~mm}^{-1}, T=293 \mathrm{~K}, \lambda=0.7107 \AA$, $\omega$ scan, reflections collected/unique reflections/parameters refined: 92906/7254/432, $R_{\text {int }}=0.0252$, final $R_{1}=0.0546(I>2 \sigma(I))$, $\mathrm{w} R_{2}=0.1842$ (all data), GOF $=1.090$. CCDC 1507998 . Crystallographic data for 2 : $\mathrm{C}_{46} \mathrm{H}_{62} \mathrm{Cl}_{4} \mathrm{Ni}_{2} \mathrm{O}_{29}(M w:$ 1338.19), orthorhombic, space group Pccn (No. 56), $a=31.1681$ (14), $b$ $=10.3152$ (4), $c=19.7265(8) \AA, \mathrm{V}=6342.2(5) \AA^{3}, Z=4$, $\rho($ cacld $)=1.401 \mathrm{gcm}^{-3}, \mu(\mathrm{MoK} \alpha)=0.842 \mathrm{~mm}^{-1}, T=293 \mathrm{~K}$, $\lambda=0.7107 \AA$, $\omega$ scan, reflections collected/unique reflections/parameters refined: $46980 / 7213 / 428, R_{\text {int }}=0.0846$, final $R_{1}=0.0725(I>2 \sigma(I)), \mathrm{w} R_{2}=0.2037$ (all data), GOF $=$ 1.072. CCDC 1507999. Crystallographic data for 3: $\mathrm{C}_{46} \mathrm{H}_{62} \mathrm{Cl}_{4} \mathrm{Co}_{2} \mathrm{O}_{29}$ (Mw: 1338.66), orthorhombic, space group $P$ ccn (No. 56), $a=31.3568$ (15), $b=10.3461$ (4), $c=19.6851$ (8) $\AA, \mathrm{V}=6386.3(5) \AA^{3}, Z=4, \rho($ cacld $)=1.392 \mathrm{gcm}^{-3}$, $\mu(\mathrm{MoK} \alpha)=0.767 \mathrm{~mm}^{-1}, T=293 \mathrm{~K}, \lambda=0.7107 \AA$, $\omega$ scan, reflections collected/unique reflections/parameters refined: $45696 / 7286 / 428, R_{\text {int }}=0.0969$, final $R_{1}=0.0894(I>2 \sigma(I))$, $\mathrm{w} R_{2}=0.2048$ (all data), GOF $=1.141$. CCDC 1508000 . Crystallographic data for 4: $\mathrm{C}_{46} \mathrm{H}_{56} \mathrm{Cl}_{4} \mathrm{Mg}_{2} \mathrm{O}_{26}(M w: 1215.35)$, orthorhombic, space group Pccn (No. 56), $a=31.3959$ (16), $b$ $=10.3773$ (5), $c=19.6850$ (9) $\AA, \mathrm{V}=6413.5$ (5) $\AA^{3}, Z=4$, $\rho($ cacld $)=1.259 \mathrm{gcm}^{-3}, \mu(\mathrm{MoK} \alpha)=0.277 \mathrm{~mm}^{-1}, T=293 \mathrm{~K}$, $\lambda=0.7107 \AA$, $\omega$ scan, reflections collected/unique reflections/parameters refined: 95161/7285/419, $R_{\text {int }}=0.0838$, final $R_{1}=0.0798(I>2 \sigma(I)), \mathrm{w} R_{2}=0.2289$ (all data), GOF $=$ 1.144. CCDC 1508001.

9 F. van Bolhuis, and C. T. Kiers, Acta Cryst. B34, 1015-1016 (1978).

10 a) M. Kaftory, in The chemistry of phenols part 1, ed. Rappoport, Z., John Wiley \& Sons: Chichester, 2003; pp 199221. b) T. H. Jordan, and T. C. W. Mak, J. Chem. Phys. 52, 3790-3794 (1970). c) K. Prout, J. Fail, R. M. Jones, R. E. Warner, and J. C. Emmett, J. Chem. Soc., Perkin Trans. 2, 265-284 (1988).

11 S. Naga, Y. Kidani, and H. Koike, Bull. Chem. Soc. Jpn. 48, (3), 863-867 (1975). 
